\title{
Prepartal high-energy feeding with grass silage-based diets does not disturb the hepatic adaptation of dairy cows during the periparturient period
}

\author{
Nanbing Qin, ${ }^{*}$ Tuomo Kokkonen, ${ }^{*}$ Siru Salin, ${ }^{*}$ Tuulikki Seppänen-Laakso,† Juhani Taponen,‡ Aila Vanhatalo, \\ and Kari Elo*1 \\ *Department of Agricultural Sciences, PO Box 28, FI-00014 University of Helsinki, Finland \\ †Industrial Biotechnology, VTT Technical Research Centre of Finland Ltd, Tietotie 2, PO Box 1000, FI-02044 VTT, Finland \\ $\ddagger$ Department of Production Animal Medicine, University of Helsinki, Paroninkuja 20, FI-04920, Saarentaus, Finland
}

\begin{abstract}
The liver of dairy cow naturally undergoes metabolic adaptation during the periparturient period in response to the increasing demand for nutrients. The hepatic adaptation is affected by prepartal energy intake level and is potentially associated with inflammatory responses. To study the changes in the liver function during the periparturient period, 16 cows (body condition score $=$ $3.7 \pm 0.3$, mean \pm standard deviation; parity $=$ second through fourth) were allocated to a grass silage-based controlled-energy diet (104 MJ/d) or a high-energy diet (135 MJ/d) during the last 6 wk before the predicted parturition. Liver samples were collected by biopsy at $8 \mathrm{~d}$ before the predicted parturition $(-8 \mathrm{~d})$ and at 1 and $9 \mathrm{~d}$ after the actual parturition ( 1 and $9 \mathrm{~d}$ ). The lipidomic profile of liver samples collected at -8 and $9 \mathrm{~d}$ was analyzed using ultra performance liquid chromatography-mass spectrometry-based lipidomics. Liver samples from all the time points were subjected to microarray analysis and the subsequent pathway analysis with Ingenuity Pathway Analysis software (Ingenuity Systems, Mountain View, CA). Prepartal energy intake level affected hepatic gene expression and lipidomic profiles prepartum, whereas little or no effect was observed postpartum. At $-8 \mathrm{~d}$, hepatic lipogenesis was promoted by prepartal high-energy feeding through the activation of $\mathrm{X}$ receptor/retinoid $\mathrm{X}$ receptor pathway and through increased transcription of thyroid hormone-responsive (THRSP). Hepatic inflammatory and acute phase responses at $-8 \mathrm{~d}$ were suppressed (z-score $=-2.236$ ) by prepartal high-energy feeding through the increase in the mRNA abundance of suppressor of cytokine signaling 3 (SOCS3) and the decrease in the mRNA abundance of interleukin 1 (IL1), nuclear factor kappa B 1 (NFKB1), apolipopro-
\end{abstract}

Received May 12, 2017.

Accepted June 8, 2018.

${ }^{1}$ Corresponding author: kari.elo@helsinki.fi tein A1 (APOA1), serum amyloid A3 (SAA3), haptoglobin $(H P)$, lipopolysaccharide-binding protein $(L B P)$, and inter- $\alpha$-trypsin inhibitor heavy chain 3 (ITIH3). Moreover, prepartal high-energy feeding elevated hepatic concentrations of C18- (7\%), C20- (17\%), C21(26\%), C23-sphingomyelins (26\%), and total saturated sphingomyelin (21\%). In addition, cows in both groups displayed increased lipogenesis at the gene expression level after parturition and alterations in the concentration of various sphingolipids between the first and last samplings. In conclusion, prepartal high-energy feeding promoted lipogenesis and suppressed inflammatory and acute phase responses in the liver before parturition, whereas only minor effects were observed after parturition.

Key words: dairy cow, periparturient period, physiological adaptation, microarray, lipidomic profiling

\section{INTRODUCTION}

Dairy cows undergo a series of physiological adaptations during the periparturient period due to the increasing energy requirement and the subsequent negative energy balance. The physiological adaptations are partly mediated by insulin resistance (IR) and the change in plasma insulin concentration (Bell and Bauman, 1997). These changes lead to the mobilization of body reserves to the tissues in demand (Bell, 1995; Vernon, 2005). Part of the mobilized nutrients are allocated to the liver, where they induce hepatic adaptation, including increased gluconeogenesis and ketogenesis (Aiello et al., 1984; Herdt, 2000). Hepatic adaptation is regulated at gene expression level, as altered mRNA abundance near calving was observed in genes involved in various metabolic pathways (Loor et al., 2005; McCarthy et al., 2010). In addition, hepatic adaptation is potentially associated with the inflammatory status, as negative energy balance is accompanied by increased inflammation induced by proinflammatory cytokines (Trevisi et al., 2012), which stimulate hepatic 
synthesis and secretion of positive acute phase proteins (Bionaz et al., 2007).

Hepatic adaptation is potentially affected by prepartal energy intake level of cows. Prepartal high-energy feeding has been reported to exacerbate the lipid mobilization from adipose tissue (AT), particularly after parturition, as characterized by the elevated plasma nonesterified fatty acid (NEFA) level (Douglas et al., 2006; Janovick et al., 2011), and evidenced by the decreased expression of lipogenic genes in AT (Selim et al., 2015). As a consequence, the liver may be supplied with the excessive abundance of NEFA, which promotes hepatic lipogenesis and may lead to various metabolic disorders (Ingvartsen, 2006; Loor et al., 2006). Moreover, excessive energy intake prepartum and increased visceral adiposity may predispose dairy cows to inflammation and impaired liver function (Loor et al., 2006). In humans and mice, inflammation is considered as a mechanism that induces IR (McArdle et al., 2013). However, there are contradicting reports whether prepartal high-energy feeding (Mann et al., 2016; Salin et al., 2017) or increased adiposity (Shahzad et al., 2014; De Koster et al., 2015) leads to increased systemic IR in periparturient cows.

Sphingolipids are a class of lipids closely associated with the glucose homeostasis in human and mice (Larsen and Tennagels, 2014). Ceramides (Cer), the most abundant sphingolipids in the cell, have been recognized to trigger IR, and their production is influenced by the inflammatory response (Chavez and Summers, 2012). In recent years, the application of lipidomics has enabled novel insights into the role of sphingolipids in the physiological adaptation in periparturient cows. Changed sphingolipid concentrations near calving were reported in the plasma, liver, AT, and skeletal muscle of cows (Imhasly et al., 2015; Qin et al., 2017; Rico et al., 2017). Comparisons between cows of different adiposity further suggested the associations between lipid mobilization and the concentrations of Cer, hexosyl ceramide (HexCer), and lactosylceramide in plasma and liver and the association between systemic IR and specific Cer during the periparturient period (Rico et al., 2015, 2017). Moreover, prepartal high-energy feeding was reported to increase the concentration of specific Cer and the total concentration of sphingomyelin (SM) in AT near calving (Qin et al., 2017).

We aimed to study effects of prepartal energy level on the hepatic adaptation of dairy cows during the periparturient period through the parallel analyses on global gene expression and lipidomic profiles. First, we hypothesized that prepartal high-energy feeding increases hepatic lipogenesis. Second, we hypothesized that prepartal high-energy feeding increases hepatic
Cer concentrations and upregulates genes related to inflammation during the periparturient period.

\section{MATERIALS AND METHODS}

\section{Animals, Diets, Samplings, and Glucose Tolerance Tests}

The feeding experiment, feed composition, and collection of biopsies were described in detail in Selim et al. (2014). Sixteen Finnish Ayrshire dairy cows were involved in the feeding experiment in a randomized complete-block design. The cows were paired according to parity (second through fourth), BW $(693 \pm 57 \mathrm{~kg}$, mean $\pm \mathrm{SD})$, and BCS $(3.7 \pm 0.3)$. The 2 cows in each pair were randomly allocated to 2 dietary treatment groups on $44 \pm 5 \mathrm{~d}$ before the actual parturition date. The grass silage-based dietary treatments included a controlled-energy (CON) diet (100\% of the energy requirement of pregnant dairy cow; Luke, 2018) and a high-energy (HE) diet targeting 150\% of the energy requirements of a pregnant cow. In the ad libitum-fed HE group, the actual average energy intake was $144 \%$ of the energy requirement of pregnant dairy cow during the first 3 wk of experimental feeding. During the last 3 wk before the predicted parturition, the energy allowance of the HE group decreased by $5 \%$ on alternate days by gradually restricting DMI as described in more detail by Salin et al. (2017). The average ME was 99 $\mathrm{MJ} / \mathrm{d}$ in the CON group and $141 \mathrm{MJ} / \mathrm{d}$ in the HE group from wk 6 to 4 prepartum, and $109 \mathrm{MJ} / \mathrm{d}$ in the CON group and $128 \mathrm{MJ} / \mathrm{d}$ in the $\mathrm{HE}$ group from wk 3 to 1 prepartum. After parturition, all cows were fed wilted grass silage ad libitum, supplemented with increasing amount of small grain-based concentrate, starting from $5 \mathrm{~kg} / \mathrm{d}$ on the day of parturition and increasing to 9 $\mathrm{kg} / \mathrm{d}$ at $9 \mathrm{~d}$ postpartum (average ME was $11 \mathrm{MJ} / \mathrm{d}$ during the first 2 wk of lactation). The liver samples were collected by biopsy $8 \mathrm{~d}$ before the predicted parturition $(11 \pm 5 \mathrm{~d}$ in the actual operation) and 1 and $9( \pm 1) \mathrm{d}$ postpartum (the 3 time points are hereafter represented as $-8 \mathrm{~d}, 1 \mathrm{~d}$, and $9 \mathrm{~d}$ ). Lipidomic and microarray analyses were conducted on 22 and 32 biopsy samples, respectively. The selection of samples was random with respect to pairs to represent the design of the whole study. Intravenous glucose tolerance tests (IVGTT) were performed on the cows $10 \pm 5 \mathrm{~d}$ before the actual parturition and $10 \pm 1 \mathrm{~d}$ postpartum, and the results have been published by Salin et al. (2017). The basal NEFA concentrations at $10 \pm 5 \mathrm{~d}$ before the parturition and $10 \pm 1 \mathrm{~d}$ postpartum were calculated by averaging the measurements on the blood samples collected 15 and 5 min before the IVGTT (Salin et al., 2017). 


\section{Lipidomic Profiling}

Liver biopsies were pulverized using Covaris CryoPrep (Covaris Inc., Woburn, MA) and an internal standard mixture containing examples of major lipid classes as esters with C17:0 fatty acid was added to the weighed aliquots of samples. Lipids were extracted (chloroform:methanol 2:1) with a Retsch Mixer Mill homogenizer (Retsch GmbH, Haan, Germany). After extraction, a mixture containing 3 labeled standards was added to control the extraction process. The whole lipidome analyses were performed with a Waters quadrupole time-of-flight Premier mass spectrometer combined with an Acquity Ultra Performance LC (Waters Corp., Milford, MA) by using an Acquity UPLC BEH C18 column $(2.1 \times 100 \mathrm{~mm}$ with $1.7 \mu \mathrm{m}$ particles $)$. The solvent system consisted of ultrapure water $(1 \% 1 \mathrm{M}$ $\left.\mathrm{NH}_{4} \mathrm{Ac}, 0.1 \% \mathrm{HCOOH}\right)$ and a mixture of acetonitrile: isopropanol (1:1, $\left.1 \% 1 M \mathrm{NH}_{4} \mathrm{Ac}, 0.1 \% \mathrm{HCOOH}\right)$. All solvents used were LC-MS-grade and reference lipids were obtained from Avanti Polar Lipids Inc. (Alabaster, $\mathrm{AL}$ ) and Larodan Fine Chemicals AB (Solna, Sweden). Quantification of all Cer, HexCer, and SM subspecies was based on the comparison with peak heights of internal standard Cer (d18:1/17:0).

The data processing using freely available MZmine 2 open-source software (http://mzmine.sourceforge.net/) included alignment of peaks, peak integration, normalization, and peak identification based on an internal spectral library. The analytical procedure was modified from that in Nygren et al. (2011), as described by Qin et al. (2017). The profiling of Cer and HexCer was carried out using the negative-electrospray ionization mode, and the profiling of SM was carried out using the positive-electrospray ionization mode. In total, 26 Cer, 6 HexCer, and 9 SM were identified and quantified ( $\mu \mathrm{mol} / \mathrm{g}$ of wet tissue) in the liver biopsies.

\section{Microarray Analysis}

Liver samples collected with biopsy were stored in a protective solution (Allprotect Tissue Reagent; Qiagen $\mathrm{GmbH}$, Hilden, Germany) at $-20^{\circ} \mathrm{C}$ before total RNA extraction. Approximately 3 to $5 \mathrm{mg}$ of liver was homogenized using a TissueRuptor homogenizer (Qiagen). Total RNA was extracted with an RNeasy Mini Kit (Qiagen) according to the manufacturer's instructions.

Quantification of total RNA was performed with a NanoDrop 1000 spectrophotometer (ThermoFisher Scientific, Waltham, MA). The quality of the RNA samples was assessed using an Agilent Bioanalyzer 2100 chip electrophoresis system and Agilent RNA 6000 Nano Kit (Agilent Technologies, Santa Clara, CA).
A total of 32 liver RNA samples were analyzed, using Affymetrix GeneChip Bovine Genome Arrays (Affymetrix Inc., Santa Clara, CA), including 5, 6, and 6 samples from the CON group and 5, 4, and 6 samples from the HE group at $-8,1$, and $9 \mathrm{~d}$, respectively. The arrays contained 24,027 probe sets, representing more than 23,000 transcripts. All RNA samples used in the array analyses showed RNA integrity number values higher than 8.9, and a total of $100 \mathrm{ng}$ of RNA were used per array. All RNA samples and arrays were preprocessed, hybridized, and scanned by Biomedicum Genomics at the University of Helsinki.

As the amount of genomic sequence information has increased, the original annotations for the Affymetrix arrays were based on incomplete information. The annotations were supplemented by interrogating sequence databases and taking into account recent information (Cow Ensembl release 86, https://www.ensembl.org/ Bos_taurus/Info/Index; National Center for Biotechnology Information Bos taurus Annotation Release 105, https://www.ncbi.nlm.nih.gov/genome/annotation _euk/Bos_taurus/105).

\section{Calculations and Statistical Analyses}

The sphingolipid subspecies were further sorted and the concentrations were summed up according to their fatty acid or sphingosine composition. The concentration of sphingolipids and further-sorted sphingolipid subclasses was $\log _{2}$-transformed to normalize the data. The transformed data were imported into SAS (release 9.3; SAS Institute, Cary, NC) for statistical analyses. The normality of residuals of the transformed data were tested with PROC MIXED and PROC UNIVARIATE procedures, using a model including diet as a fixed effect and pair as a random effect. The repeated-measures ANOVA was performed using PROC MIXED procedure, in which treatment, time, and their interaction were set as fixed effects, pair and the interaction between pair and time were set as random effects, and animal was set as a within-subject effect. Three covariance structures were applied in the analyses, including compound symmetry, unstructured, and spatial power law. The structure giving the smallest Bayesian information criterion was eventually selected. The SLICE option of the PROC MIXED procedure was used to test the effect of diet within each time point. $P$-values lower than 0.05 were considered significant and those of $0.05<P<$ 0.10 represented tendencies toward significance. Heatmaps were composed based on the original concentration of all sphingolipid subspecies with MetaboAnalyst 3.0 (http://www.metaboanalyst.ca/, Xia Lab, McGill University, Ste. Anne de Bellevue, Quebec, Canada; 
Xia et al., 2015). Spearman correlation analyses were performed between hepatic lipid concentrations, and the relative expression levels of selected hepatic genes obtained from the microarray analysis or the previous quantitative PCR (qPCR) analyses (Selim et al., 2014) and parameters from IVGTT (Salin et al., 2017) using PROC CORR procedure.

The analysis of microarray data, including quality control, preprocessing, normalization, and statistical analysis, was carried out using R (https: / www.r-project .org/), Bioconductor (https://www.bioconductor.org/ ), and Chipster software package (v. 3.9, CSC-IT Center for Science Ltd., Espoo, Finland; Kallio et al., 2011). With Simpleaffy package in R software, a plot of quality-control metrics was performed for all 32 arrays to test the comparability of the scaling factors. Using Chipster software, we prepared an RNA degradation plot of all the arrays and spike-in-performance log-log plots of the signal intensity versus the RNA concentration for all 32 microarrays to further analyze the quality of the array hybridizations. The normalization was performed using the robust multiarray average method (Irizarry et al., 2003). The quality of the normalized data were evaluated with the box plots of the relative log expression and normalized unscaled standard error in Chipster. The variance in gene expression between the HE and CON groups was analyzed using the localpooled-error test within the 3 time points (Jain et al., 2003). A false discovery rate control was performed on the $P$-values obtained based on the method described by Benjamini and Hochberg (2000), generating a new data set of adjusted $P$-values. The genes with adjusted $P<0.05$ were defined as the differentially expressed genes (DEG) between the 2 groups. The variance in gene expression over time was analyzed between all the time points ( -8 vs. $1 \mathrm{~d}, 1$ vs. 9 d, and -8 vs. 9 d), using the linear model in Chipster, with diet and time as the main effects after pairing the data from the same cow, followed by the same false discovery rate control described above. Genes with adjusted $P<0.05$ were considered to have different transcription levels between time points. The microarray data are available at the Gene Expression Omnibus page (https://www.ncbi .nlm.nih.gov/geo/) under accession number GSE97437.

The microarray data were further analyzed with Ingenuity Pathway Analysis (IPA) System (v. 7.5; Ingenuity Systems, Mountain View, CA; http://www ingenuity.com). The input of the pathway analyses included DEG identified in the microarray analysis and those identified in the previous qPCR with the ANOVA between the $\mathrm{CON}$ and $\mathrm{HE}$ groups at all 3 time points (Selim et al., 2014). A data set of DEG, containing their gene symbols, $P$-values, and the log ratios of their expression in the HE group to that in the CON group was imported into IPA. The genes in the data set were mapped in IPA according to their gene symbols based on Ingenuity human and rodent knowledge base. The DEG were grouped into canonical pathways, functions, and diseases based on the right-tailed Fisher Exact Test, which is a measurement of the likelihood that the association between a set of DEG in the experiment and a given process or pathway is due to random chance. Networks of the DEG were composed based on the connection between genes, as referenced from previous literature. The networks were ranked according to their scores, calculated from the number of network eligible DEG in 1 network, the total number of network eligible DEG in the whole analysis, and the total number of molecules that potentially make up this network based on the knowledge base (Jiménez-Marín et al., 2009).

\section{RESULTS}

\section{Sphingolipid Profiles in the Liver}

The most abundant Cer subspecies in the liver at -8 and $9 \mathrm{~d}$ were Cer (24:0), Cer (23:0), and Cer (22:0), taking up 23.6, 21.3, and $17.8 \%$ of the total Cer, respectively. Ceramide subspecies containing an SFA comprised $86.7 \%$ of the total Cer, with the remainder containing a MUFA. From the aspect of sphingosine profiles, Cer (d18:1) represented $89.9 \%$ of the total Cer in the liver. Among SM, C16- and C23-SM were the top 2 abundant subclasses in the liver, comprising 43.0 and $31.4 \%$ of the total SM in concentration. Eightyfive percent of the SM contained an SFA, with those containing a MUFA forming the rest.

The heatmap showed that higher level of sphingolipids tended to appear in the liver of the HE group than in the CON group at $-8 \mathrm{~d}$ (Figure 1). In contrast, the difference in sphingolipid concentrations between the groups was much less apparent at $9 \mathrm{~d}$. The further statistical analyses on sorted sphingolipid subclasses showed that the concentrations of Cer $(23: 0 ; P=$ $0.088)$, Cer $(23: 1 ; P=0.099)$, Cer $(24: 1 ; P=0.080)$, and Cer $(25: 1 ; P=0.052)$ tended to be higher in the HE group compared with the CON group (Table 1). The comparison within time points showed that the different levels of Cer $(24: 1 ; P=0.020)$ and Cer $(25: 1$; $P=0.019)$ between groups were mainly contributed by the difference in their prepartal concentrations. None of the Cer subspecies differed in concentration after parturition. The majority of Cer subspecies displaying different concentrations between groups were MUFA-Cer, which are also shown by a tendency toward higher $(P=$ 0.081) total MUFA-Cer concentrations in the HE group than in the CON group (Table 1). In addition, prepartal high-energy feeding elevated the concentrations of 


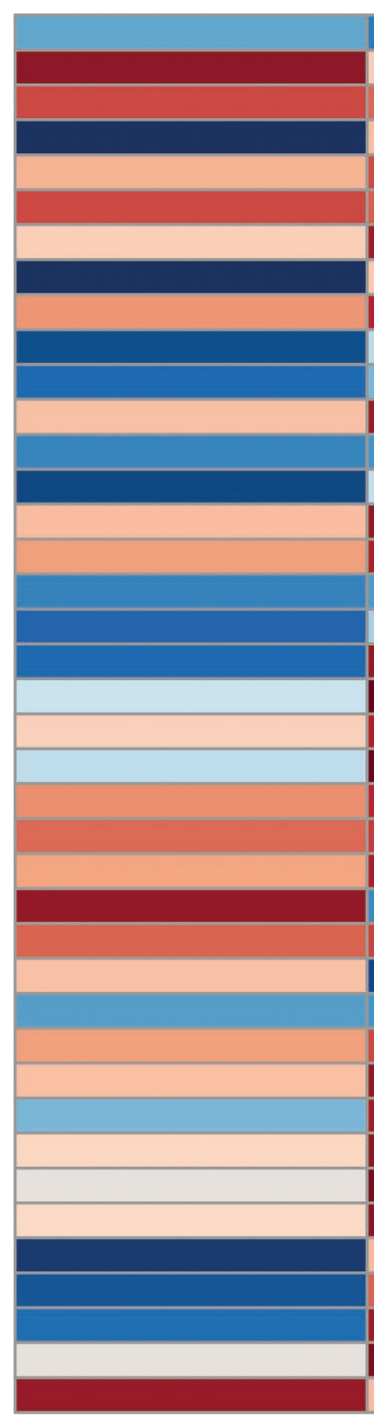

CON, $-8 d$

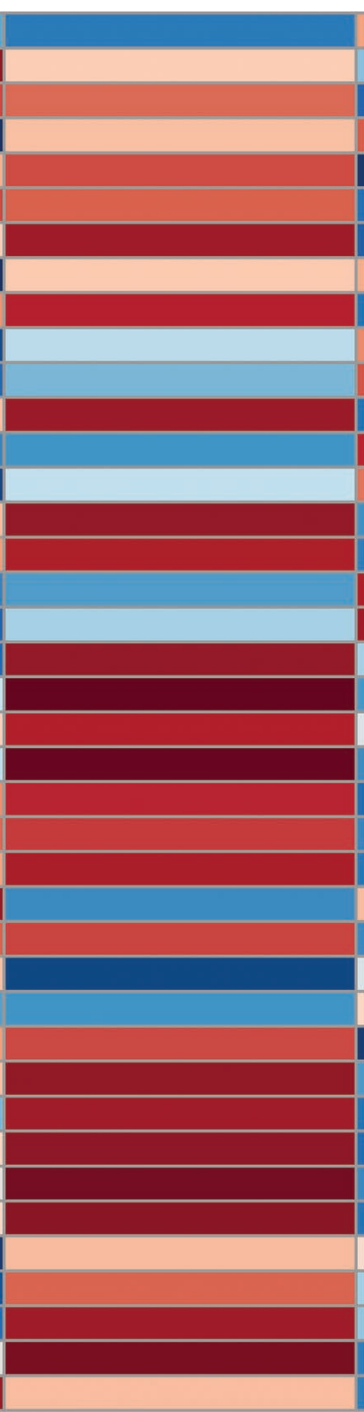

$H E,-8 d$

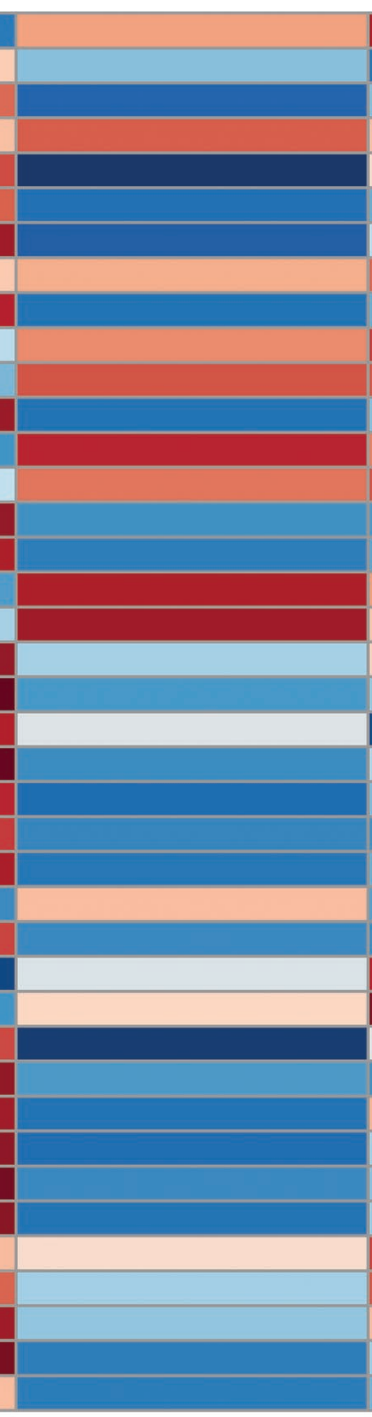

$\operatorname{CON}, 9 \mathrm{~d}$

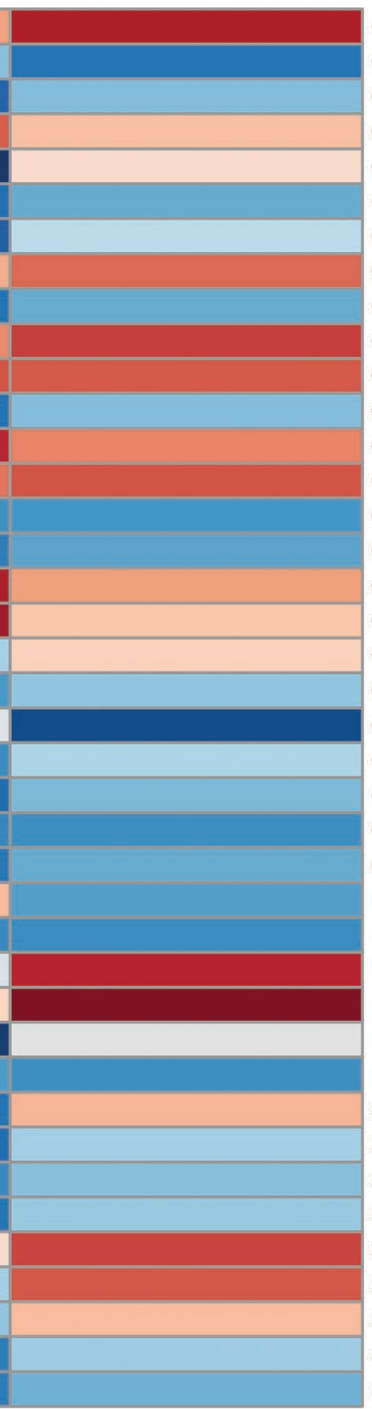

$\mathrm{HE}, 9 \mathrm{~d}$

Figure 1. Heatmap of sphingolipid concentrations in the controlled-energy (CON) feeding group and high-energy (HE) feeding group at $8 \mathrm{~d}$ before the predicted parturition $(-8 \mathrm{~d})$ and $9 \mathrm{~d}$ after the actual parturition $(9 \mathrm{~d})$. The concentration of sphingolipids was scaled based on their magnitude, represented by the intensity of gray color. Comparisons should be made within sphingolipid subspecies. The names of subspecies were formatted as sphingolipid type (sphingosine composition/fatty acid composition). Cer $=$ ceramide; HexCer $=$ hexosylceramide; SM $=$ sphingomyelin. $\nmid P<0.10 ; * P<0.05 ; * * P<0.01 ; * * * P<0.005$. Color version available online.

C18- $(P=0.007), \mathrm{C} 20-(P=0.004), \mathrm{C} 21-(P=0.035)$, and C23-SM $(P<0.001)$, and the total concentration of saturated SM $(P=0.004)$ in the HE group compared with the CON group (Table 1). Similar to Cer, the comparison within time points showed that the significant effect $(P<0.05)$ of prepartal high-energy feeding on SM was mainly derived prepartum.

Considering the change of sphingolipids in the liver over time regardless of the diet, the heatmap showed that the concentration of most HexCer and SM subspecies decreased from -8 to 9 d, with HexCer (d18:1/ 23:0), HexCer (d18:1/22:0), SM (d18:1/20:0), and SM (d18:1/21:0) being the exceptions (Figure 1). The patterns in Cer concentrations over time varied with the length of their acyl chains. Moreover, the number of double bonds in the acyl chain and the sphingosine type also influenced the patterns in Cer concentrations over time. For instance, we observed contrasting patterns over time between Cer (d18:1/20:0) and Cer (d18: 2/20:0) and between Cer (d18:1/24:0) and Cer (d18: 1/24:1). Further statistical analyses showed significant declines over time in several Cer subclasses, including Cer $(18: 0 ; P=0.042)$, Cer $(23: 1 ; P=0.014)$, Cer $(25: 1$; $P=0.025)$, Cer $(26: 0 ; P<0.001)$, and Cer $(26: 1 ; P$ 
$<$ 0.001; Supplemental Table S1, https://doi.org/10 $.3168 /$ jds.2017-13153). An exception, an increase $(P$ $=0.030)$ from -8 to $9 \mathrm{~d}$ was observed in Cer $(23: 0)$. From the aspect of sphingosine profiles, we observed significant increases in Cer (d17:1; $P=0.044)$ and Cer (d18:0; $P=0.014)$ concentrations, whereas a decrease $(P<0.001)$ in Cer $(\mathrm{d} 18: 2)$ concentration from -8 to 9 d was observed (Supplemental Table S1). In addition, significant decreases over time were observed in various SM subclasses, including C16- $(P=0.037), \mathrm{C} 18-(P=$ $0.011)$, C24- $(P=0.036)$, and MUFA-SM $(P=0.002)$.

\section{Pathway Analyses on DEG Between the Feeding Groups}

In the microarray analysis, we identified 106, 67 , and 52 DEG between the 2 groups at $-8,1$, and $9 \mathrm{~d}$, respectively. Subsequently, IPA software successfully mapped 74 genes at $-8 \mathrm{~d}, 43$ genes at $1 \mathrm{~d}$, and 36 genes at 9 d (Supplemental Table S2; https://doi.org/10.3168/jds .2017-13153) and grouped these genes into pathways, functions, and diseases (Table 2). We identified 57, 52, and 29 pathways with $P<0.05$ at $-8,1$, and $9 \mathrm{~d}$, respectively, in the canonical pathway analyses in IPA. Of these, only 2 pathways at $-8 \mathrm{~d}$ displayed significant difference between the $\mathrm{HE}$ and $\mathrm{CON}$ group based on the calculation of z-score (Supplemental Figure S1; https:// doi.org/10.3168/jds.2017-13153); that is, the downregulation of acute phase response signaling (z-score $=$ -2.236; $P<0.0001$; Supplemental Figure S2, https:// doi.org/10.3168/jds.2017-13153) and the upregulation of liver $\mathrm{X}$ receptor/retinoid $\mathrm{X}$ receptor $(L X R / R X R)$ activation (z-score $=0.816 ; P<0.0001$; Supplemental Figure S3, https://doi.org/10.3168/jds.2017-13153). The downregulation of acute phase response signaling was characterized by the upregulated transcription of suppressor of cytokine signaling 3 (SOCS3) and the downregulated transcription of interleukin 1 (IL1), nuclear factor kappa B 1 (NFKB1), apolipoprotein A1 (APOA1), serum amyloid A3 (SAA3), haptoglobin $(H P)$, lipopolysaccharide-binding protein $(L B P)$, and inter- $\alpha$-trypsin inhibitor heavy chain 3 (ITIH3). The upregulation of $L X R / R X R$ activation pathway was characterized by the upregulated transcription of apolipoprotein A4 (APOA4) and the downregulated transcription of APOA1, IL1, LBP, and NFKB1. In contrast, we observed no significant pattern in pathways at 1 and $9 \mathrm{~d}$. In the network analyses, we identified 2 gene networks containing more than 20 DEG [i.e., lipid metabolism, small-molecule biochemistry, and vitamin

Table 1. Concentration of sphingolipid subclasses that showed significant difference $(P<0.05)$ or tendencies toward significant $(P<0.10)$ difference between the feeding groups at $8 \mathrm{~d}$ before parturition $(-8 \mathrm{~d})$ and $9 \mathrm{~d}$ postpartum $(9 \mathrm{~d})^{1}$

\begin{tabular}{|c|c|c|c|c|c|c|c|}
\hline \multirow{2}{*}{$\begin{array}{l}\text { Lipid } \\
\text { subclass }\end{array}$} & & \multicolumn{2}{|c|}{ Mean $^{2}$} & \multirow[b]{2}{*}{ SEM } & \multicolumn{3}{|c|}{$P$-value } \\
\hline & & $\mathrm{CON}$ & $\mathrm{HE}$ & & Diet & Day & Diet $\times$ day \\
\hline$\overline{\operatorname{Cer}(23: 0)^{3}}$ & $\begin{array}{r}-8 \mathrm{~d} \\
9 \mathrm{~d}\end{array}$ & $\begin{array}{l}-2.02 \\
-1.68\end{array}$ & $\begin{array}{l}-1.84 \\
-1.66\end{array}$ & 0.057 & 0.088 & 0.030 & 0.429 \\
\hline Cer $(23: 1)$ & $\begin{array}{r}-8 \mathrm{~d} \\
9 \mathrm{~d}\end{array}$ & $\begin{array}{l}-3.97 \\
-4.27\end{array}$ & $\begin{array}{l}-3.77 \\
-4.24\end{array}$ & 0.075 & 0.099 & 0.014 & 0.415 \\
\hline Cer $(24: 1)$ & $\begin{array}{r}-8 \mathrm{~d} \\
9 \mathrm{~d}\end{array}$ & $\begin{array}{l}-3.60 \\
-3.54\end{array}$ & $\begin{array}{l}-3.22^{*} \\
-3.41\end{array}$ & 0.090 & 0.080 & 0.540 & 0.083 \\
\hline Cer $(25: 1)$ & $\begin{array}{r}-8 \mathrm{~d} \\
9 \mathrm{~d}\end{array}$ & $\begin{array}{l}-5.31 \\
-5.46\end{array}$ & $\begin{array}{l}-4.91^{*} \\
-5.34\end{array}$ & 0.081 & 0.052 & 0.025 & 0.231 \\
\hline Saturated Cer & $\begin{array}{r}-8 \mathrm{~d} \\
9 \mathrm{~d}\end{array}$ & $\begin{array}{l}-2.53 \\
-2.63\end{array}$ & $\begin{array}{l}-2.22 \\
-2.54\end{array}$ & 0.076 & 0.081 & 0.066 & 0.161 \\
\hline SM (C18) & $\begin{array}{r}-8 \mathrm{~d} \\
9 \mathrm{~d}\end{array}$ & $\begin{array}{l}-4.44 \\
-4.60\end{array}$ & $\begin{array}{l}-4.23 \dagger \\
-4.49\end{array}$ & 0.062 & 0.007 & 0.011 & 0.542 \\
\hline SM (C20) & $\begin{array}{r}-8 \mathrm{~d} \\
9 \mathrm{~d}\end{array}$ & $\begin{array}{l}-5.93 \\
-5.70\end{array}$ & $\begin{array}{l}-5.62^{*} \\
-5.56\end{array}$ & 0.093 & 0.004 & 0.281 & 0.541 \\
\hline $\mathrm{SM}$ (C21) & $\begin{array}{r}-8 \mathrm{~d} \\
9 \mathrm{~d}\end{array}$ & $\begin{array}{l}-5.40 \\
-5.21\end{array}$ & $\begin{array}{l}-4.97 \dagger \\
-4.96\end{array}$ & 0.106 & 0.035 & 0.506 & 0.624 \\
\hline $\mathrm{SM}(\mathrm{C} 23)$ & $\begin{array}{r}-8 \mathrm{~d} \\
9 \mathrm{~d}\end{array}$ & $\begin{array}{l}-2.40 \\
-2.33\end{array}$ & $\begin{array}{l}-1.93^{*} \\
-2.13\end{array}$ & 0.078 & $<0.001$ & 0.614 & 0.193 \\
\hline Saturated SM & $\begin{array}{r}-8 \mathrm{~d} \\
9 \mathrm{~d}\end{array}$ & $\begin{array}{l}-0.86 \\
-0.97\end{array}$ & $\begin{array}{l}-0.51^{*} \\
-0.78\end{array}$ & 0.080 & 0.004 & 0.167 & 0.430 \\
\hline
\end{tabular}

${ }^{1} \mathrm{HE}=$ high-energy feeding group (targeted at 150\% of the energy requirement of a pregnant dairy cow); CON $=$ controlled-energy feeding group ( $100 \%$ of the energy requirement of a pregnant dairy cow); Cer $=$ ceramide; $\mathrm{SM}=$ sphingomyelin.

${ }^{2}$ The mean values in the table were $\log _{2}$-transformed from the original concentrations ( $\mu \mathrm{mol} / \mathrm{g}$ of tissue).

${ }^{3}$ The content in parentheses indicates the fatty acid composition.

$\dagger=P<0.10 ;{ }^{*}=P<0.05$. 
Table 2. Summary of the most significant differentially expressed genes (DEG), diseases, and biological functions in ingenuity pathway analyses $(\mathrm{IPA})^{1}$

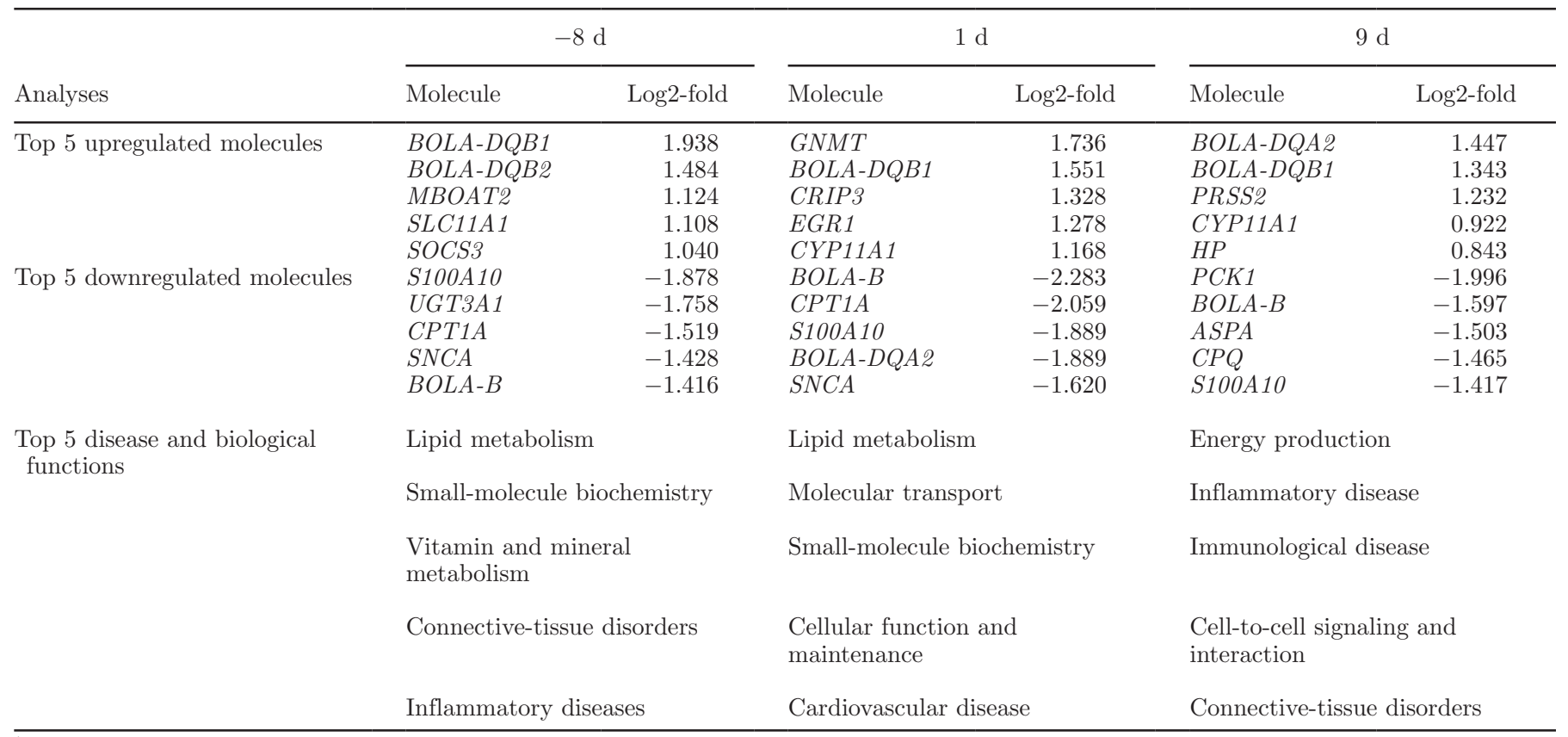

${ }^{1} B O L A-D Q B 1=$ histocompatibility complex, class II, DQ $\beta$, type $1 ; B O L A-D Q B 2=$ histocompatibility complex, class II, DQ $\beta$, type 2 ; $M B O A T 2=$ membrane-bound O-acyltransferase domain containing type $2 ; S L C 11 A 1=$ solute carrier family 11 member A1; SOCS3 = suppressor of cytokine signaling $3 ; S 100 A 10=$ S100 calcium-binding protein A10; UGT3A1 = UDP glycosyltransferase family 3, polypeptide A1; $C P T 1 A=$ carnitine palmitoyltransferase $1 \mathrm{~A} ; S N C A=$ synuclein $\alpha ; B O L A-B=$ major histocompatibility complex, class $\mathrm{I}$, B; $G N M T=$ glycine N-methyltransferase; $C R I P 3=$ cysteine-rich protein $3 ; E G R 1=$ early growth response $1 ; C Y P 11 A 1=$ cytochrome P450, family 11 , subfamily A, polypeptide 1; BOLA-DQA2 = histocompatibility complex, class II, DQ a 2; PRSS2 = protease, serine S2; HP = haptoglobin; PCK1 = phosphoenolpyruvate carboxykinase $1 ; A S P A=$ aspartoacylase; $C P Q=$ carboxypeptidase $\mathrm{Q}$.

and mineral metabolism (score 51, 22 focus molecules) at $-8 \mathrm{~d}$ and connective-tissue disorders, inflammatory disease, and skeletal and muscular disorders (score 53, 20 focus molecules) at $9 \mathrm{~d}]$. The network identified at $-8 \mathrm{~d}$ displayed the association between the DEG in the significant canonical pathways and other DEG (Supplemental Figure S4; https://doi.org/10.3168/jds .2017-13153).

\section{Changes in Gene Expression over Time}

We observed that 158 genes were differentially expressed for 1 versus $-8 \mathrm{~d}$. The numbers were 383 for 9 versus $1 \mathrm{~d}$ and 654 for 9 versus $-8 \mathrm{~d}$ (adjusted $P$ $<0.05$ ). The DEG between time points involved in inflammatory response, acute phase response, sphingolipid metabolism, and lipogenesis are presented (Figure 2 and Figure 3).

\section{Correlation Analyses}

We observed negative correlations between BCS at 2 wk prepartum and the hepatic concentration of various
Cer subclasses at $-8 \mathrm{~d}$, including Cer (18:0; $\mathrm{r}=-0.79$; $P=0.001)$, Cer $(19: 0 ; \mathrm{r}=-0.60 ; P=0.030)$, Cer $(24: 0 ; \mathrm{r}=-0.66 ; P=0.014)$, Cer $(25: 1 ; \mathrm{r}=-0.60$; $P=0.029)$, Cer $(26: 0 ; \mathrm{r}=-0.66 ; P=0.014)$, and Cer $(26: 1 ; \mathrm{r}=-0.77 ; P=0.002)$. In addition, plasma NEFA concentration was negatively correlated with various Cer subclasses; for example, Cer (18:0) prepartum $(\mathrm{r}=-0.63 ; P=0.039)$ and $\operatorname{Cer}(16: 0)$ postpartum $(\mathrm{r}=-0.77 ; P=0.005)$. Glucose area under curve in IVGTT postpartum was negatively correlated with hepatic concentration of various Cer subspecies at $9 \mathrm{~d}$, including Cer (18:0; $\mathrm{r}=-0.64 ; P=0.035)$, Cer $(23: 0 ; \mathrm{r}$ $=-0.65 ; P=0.029)$, Cer $(24: 0 ; \mathrm{r}=-0.80 ; P=0.003)$, and Cer $(25: 0 ; \mathrm{r}=-0.72 ; P=0.013)$. The relative expression level of $S A A 3$ in microarray was negatively correlated with hepatic C18-SM concentration at $-8 \mathrm{~d}$ $(\mathrm{r}=-0.71 ; P=0.047)$. The relative expression level of $L B P$ in microarray was negatively correlated with hepatic concentrations of $\mathrm{C} 16-(\mathrm{r}=-0.74 ; P=0.037)$ and $\mathrm{C} 18-\mathrm{SM}(\mathrm{r}=-0.90 ; P=0.002)$ at $-8 \mathrm{~d}$. The relative expression level of $I L 1 A$ in microarray was negatively correlated with hepatic C20-SM concentration (r $=-0.76 ; P=0.028)$ at $-8 \mathrm{~d}$. 


\section{DISCUSSION}

This study presents the changes in hepatic lipidomic and gene expression profiles during the periparturient period in response to different prepartal energy intake levels. Parts of the results from the same experiment were published in earlier papers, including the whole lipidome analyses in the liver and AT (Qin et al., 2017), the IVGTT results (Salin et al., 2017), and the measurements of animal performance and blood metabolites as well as the qPCR analyses of 7 hepatic genes involved in insulin signaling, inflammatory response, and gluconeogenesis (Selim et al., 2014). Despite the marked difference in energy intake between the 2 feeding groups, we found no diet effect in either BW change (1.3 vs. $1.1 \mathrm{~kg} / \mathrm{d}$; HE vs. CON) during the dry period or BCS before calving (3.7 vs. 3.8; HE vs. CON). However, we observed that the HE had lower basal blood NEFA concentration than the CON group in IVGTT at $1 \mathrm{wk}$ before parturition (Salin et al., 2017). In contrast, the basal NEFA levels after parturition were not different between the feeding groups (Salin et al., 2017). In addi-
SPTSSA

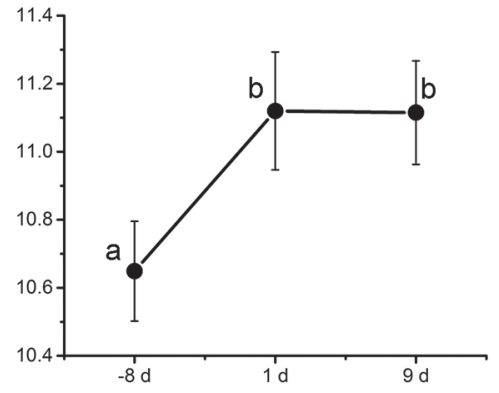

SAA4

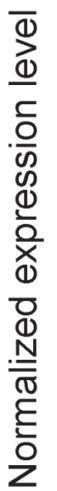

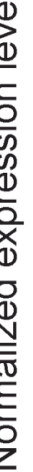

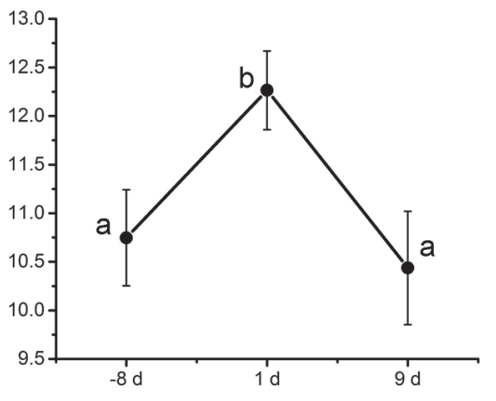

IL1R2

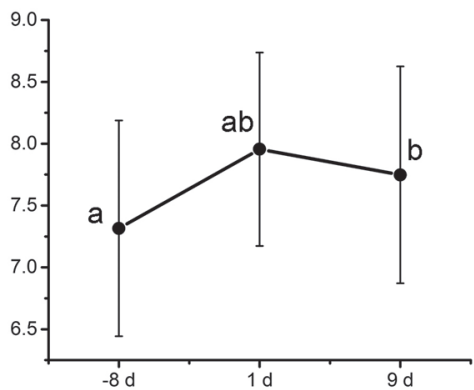

SPTSSB

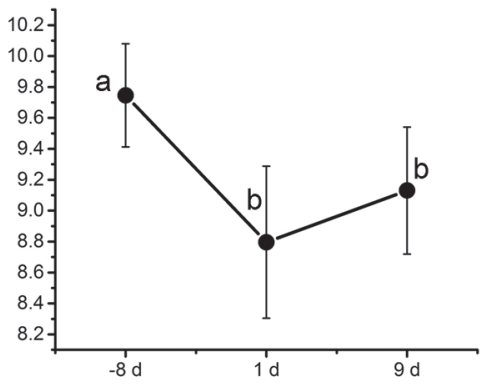

HP

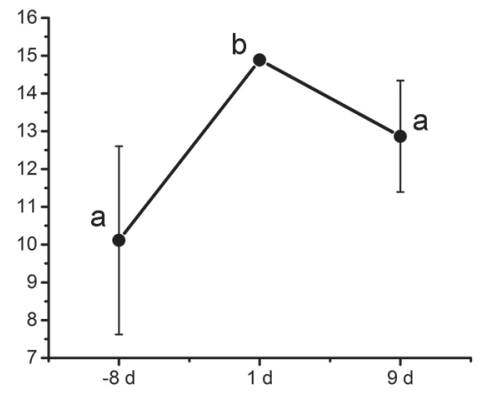

IL4R

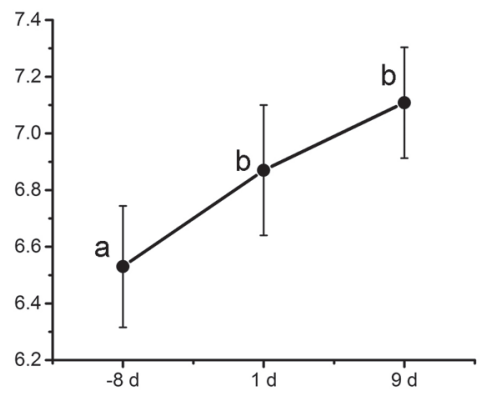

Time relative to parturition
SAA3

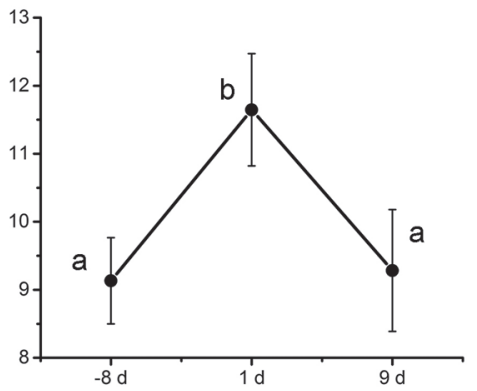

$L B P$

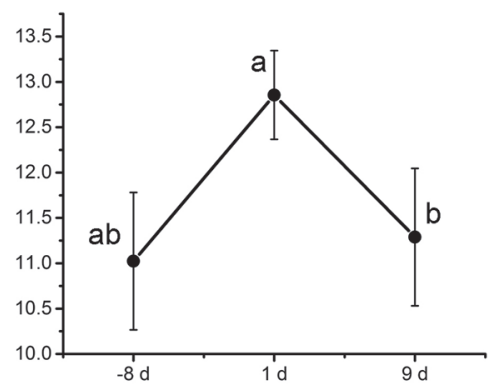

IL10RB

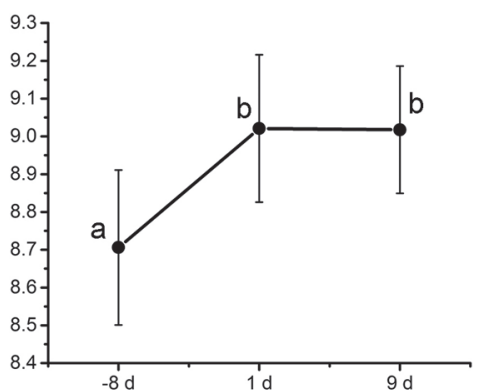

Figure 2. Normalized expression level of genes involved in ceramide metabolism, acute phase response, and inflammatory response at $8 \mathrm{~d}$ before the predicted parturition $(-8 \mathrm{~d}), 1 \mathrm{~d}$ after the actual parturition $(1 \mathrm{~d})$, and $9 \mathrm{~d}$ after the actual parturition $(9 \mathrm{~d})$. Different letters (a,b) indicate significant differences $(P<0.05) . S P T S S A=$ serine palmitoyltransferase small subunit A; SPTSSB = serine palmitoyltransferase small subunit B; $S A A 3=$ serum amyloid A3; SAA4 = serum amyloid A4; $H P=$ haptoglobin; $L B P=$ lipopolysaccharide-binding protein; $I L 1 R 2=$ interleukin 1 receptor type $2 ; I L 4 R=$ interleukin 4 receptor; IL10RB = interleukin 10 receptor subunit $\beta$. Error bars indicate the SE of the normalized expression level. 

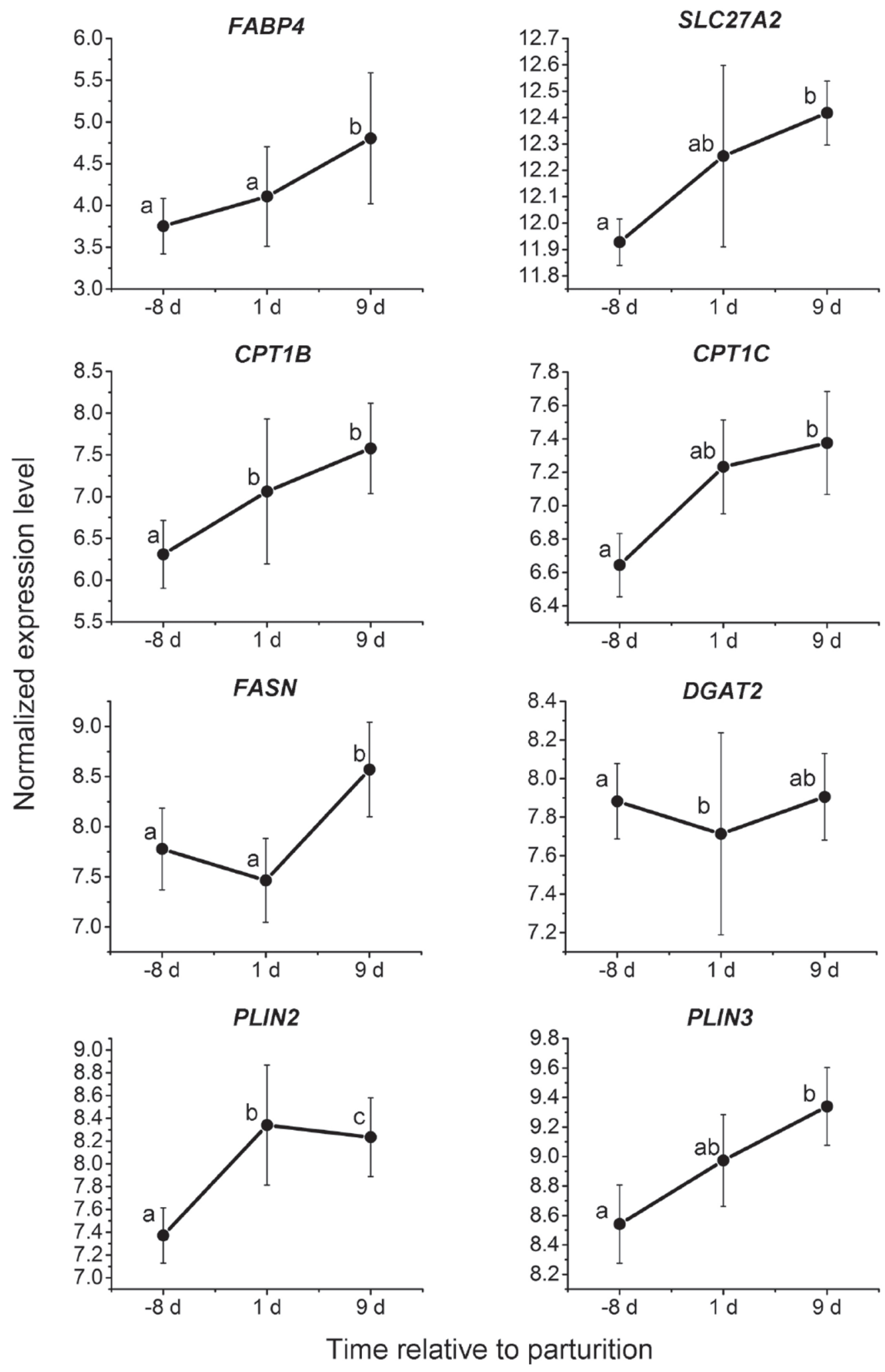

Figure 3. Normalized expression level of genes involved in lipid metabolism at $8 \mathrm{~d}$ before the predicted parturition $(-8 \mathrm{~d}), 1 \mathrm{~d}$ after the actual parturition $(1 \mathrm{~d})$, and $9 \mathrm{~d}$ after the actual parturition $(9 \mathrm{~d})$. Different letters $(\mathrm{a}-\mathrm{c})$ indicate significant differences $(P<0.05) . F A B P 4=$ fatty acid binding protein $4 ; S L C 27 A 2=$ solute carrier family 27 member A2; $C P T 1 B=$ carnitine palmitoyltransferase $1 \mathrm{~B} ; C P T 1 C=$ carnitine palmitoyltransferase 1C; DGAT2 = diacylglycerol O-acyltransferase $2 ; F A S N=$ fatty acid synthase; PLIN2 = perilipin $2 ;$ PLIN3 = perilipin 3 . Error bars indicate the SE of the normalized expression level. 
tion, results from IVGTT suggested little or no difference in whole body insulin sensitivity between the HE and $\mathrm{CON}$ group at $1 \mathrm{wk}$ before parturition compared to 1 wk postpartum (Salin et al., 2017). Analogous to our previous results, the present results showed a greater effect of prepartal energy level on both the lipidomic and gene expression profiles before parturition than after.

\section{Hepatic Lipogenesis}

Previously we reported that the HE group had higher hepatic total lipid concentration compared with the CON group at -8 and $9 \mathrm{~d}$ (Qin et al., 2017). At the gene expression level, the increase of total lipid concentration under prepartal high-energy feeding was reflected by the upregulation of $L X R / R X R$ activation pathway in the $\mathrm{HE}$ group compared with the CON group at $-8 \mathrm{~d}$ because $L X R / R X R$ activation is a pathway that promotes lipogenesis by stimulating sterol regulatory element-binding protein 1c (Schultz et al., 2000). However, we observed no differential expression in the single genes of nuclear receptors $L X R$ and $R X R$ between groups, although the pathway was identified as significantly upregulated in the canonical pathway analysis. The increase in lipogenesis was supported by the upregulation of thyroid hormone-responsive (THRSP) in the HE group compared with the CON group at the same time point (Supplemental Figure S4, https://doi.org/10.3168/jds.2017-13153). The gene THRSP promotes hepatic lipogenesis, and its expression is regulated by $L X R \alpha$ through a sterol regulatory element-binding protein 1c-dependent mechanism in mice (Wu et al., 2013). The lipogenic role of THRSP was previously reported in the mammary epithelial cell of ruminants (Cui et al., 2015; Yao et al., 2016). Previously, Khan et al. (2014) reported that high-energy feeding during the entire dry period increased hepatic transcription of various lipogenic genes before parturition, including THRSP. However, the difference in the feeding approaches between our study and Khan et al. (2014) may decrease the comparability between results. We gradually reduced the energy allowance in the HE group during the close-up period. This was not applied in Khan et al. (2014), although they observed a gradual decrease in DMI when approaching calving.

Earlier studies have shown that the high-energy intake during the far-off dry period is often associated with a decline of DMI during the close-up dry period, and the decline has been up to $30 \%$ in corn silagebased diet (Grummer et al., 2004). This has led to the decreased difference in energy balance between the treatments with ad libitum and the controlled-energy feeding (Dann et al., 2006). Based on these findings, we manipulated the feed intake in the HE group by decreasing the energy allowance by $5 \%$ on alternate days through the gradual restriction of DMI during the last $3 \mathrm{wk}$ before parturition (Salin et al., 2017) to test whether the high-energy feeding during the early dry period accompanied by a large decline of feed intake during the close-up dry period was detrimental to the physiological adaptation of dairy cows in grass silagebased feeding. It is worth noting that the high-energy feeding still increased the average energy allowance by $30 \%$ compared with the control during the whole experimental period (135 vs. $104 \mathrm{MJ} / \mathrm{d}$ ). Indeed, Dann et al. (2006) reported that the high-energy feeding during the far-off dry period had significant negative effects on the periparturient metabolism of dairy cows, whereas no effect was observed for the high-energy feeding during the close-up dry period. In the present study, the difference in energy intake between the HE $(140 \%$ of CON during wk 6 and 4 before parturition) and CON group was profound during the far-off dry period. Therefore, it is profitable to compare our results with other highenergy feeding studies.

As reported in our earlier publication, the HE group had lower plasma NEFA concentration prepartum compared with the CON group. Despite the decrease in plasma NEFA, the HE group displayed upregulated hepatic lipogenesis before parturition based on the results from the microarray analysis. In the previous $\mathrm{qPCR}$ analyses on the same animals, we observed potentially suppressed fatty acid oxidation in the liver of the $\mathrm{HE}$ group compared with the CON group, based on the expression profile of carnitine palmitoyltransferase 1A (CPT1A; Selim et al., 2014), which encodes the CPT1 enzyme that facilitates the entry of fatty acids into mitochondria (Drackley et al., 2001). We suggest that the suppressed fatty acid oxidation under high-energy feeding may have outweighed the decrease in hepatic NEFA uptake and, thus, may have compensated for the lower influx of fatty acids in the liver, ultimately leading to the net increase in hepatic lipogenesis in the HE group compared with the CON group before parturition. The corresponding result was reported by Loor et al. (2006), showing that overfed cows had lower plasma NEFA levels and lower expression of genes related to hepatic fatty acid oxidation prepartum compared with cows in a restricted-energy diet.

The stimulation of lipogenic pathways by the prepartal high-energy feeding disappeared after parturition. Moreover, the cows on the HE diet showed no greater lipid accumulation in the liver than did the cows in the CON diet after parturition (Qin et al., 2017). However, regardless of the diet, the cows displayed the 
accumulation of lipid in the liver after parturition, as suggested by the dramatic increases in the concentration of triacylglycerol (TAG) and its precursor diacylglycerol from -8 to $9 \mathrm{~d}$ (Qin et al., 2017). The lipid accumulation was reflected by the expression profiles of various lipogenic genes over time (Figure 3). The transcription of fatty acid transporters, including fatty acid binding protein 4 (FABP4) and solute carrier family 27 member A2 (SLC27A2), increased from 1 to 9 $\mathrm{d}$, suggesting a potential increase in hepatic NEFA uptake from the onset of lactation. A similar pattern was previously reported on another fatty acid transporter, showing that hepatic expression of solute carrier family 27 member A1 (SLC27A1) in dairy cows was higher at 1 wk postpartum than at 3 wk prepartum (Gross et al., 2013). Increased NEFA influx after parturition may subsequently stimulate hepatic fatty acid oxidation, reflected by the upregulated hepatic transcription of carnitine palmitoyltransferase $1 \mathrm{~B}(C P T 1 B)$ and carnitine palmitoyltransferase $1 \mathrm{C}(C P T 1 C)$ from -8 to $9 \mathrm{~d}$. The activation of the CPT1-encoding genes after parturition corresponds to the previous findings of others (Drackley et al., 2005; Akbar et al., 2013; Khan et al., 2014). The transcription of fatty acid synthase $(F A S N)$ and diacylglycerol O-acyltransferase 2 (DGAT2) was higher at $9 \mathrm{~d}$ compared with -8 or $1 \mathrm{~d}$, suggesting potentially increased hepatic fatty acid and TAG syntheses after parturition; this was in line with the finding of Gross et al. (2013), who observed that hepatic FASN expression increased dramatically from $3 \mathrm{wk}$ prepartum to 1 wk postpartum. In the liver, TAG is stored as lipid droplets, with perilipins (PLIN) forming the surface. We observed higher expression of PLIN2 and PLIN3 at $9 \mathrm{~d}$ relative to $-8 \mathrm{~d}$ in both groups, which supports the increased TAG storage as lipid droplets in the liver after parturition and corresponds to the finding of Akbar et al. (2013), who showed that hepatic PLIN2 expression in dairy cows increased from $14 \mathrm{~d}$ prepartum to $10 \mathrm{~d}$ postpartum. Collectively, the gene expression profiles reflected greater lipid storage and more active lipogenesis in the liver at $1 \mathrm{wk}$ postpartum than at 1 wk before parturition.

\section{Hepatic Inflammatory and Acute Phase Responses}

Prepartal high-energy feeding downregulated the acute phase response signaling pathway at $-8 \mathrm{~d}$ based on the gene expression analysis. In cattle, acute phase response proteins have been defined as indicators of inflammation and fatty liver disease (Nakagawa et al., 1997; Saremi et al., 2013). The downregulation of $S A A 3, H P$, and $L B P$ may reflect a lower grade of inflammation in the liver of the HE group rather than in the CON group at $-8 \mathrm{~d}$. This was supported by the downregulation of the proinflammatory genes IL1 and NFKB1 in the HE group compared with the CON group at the same time point, as these genes participate in the mediation of the acute phase response, according to findings in mice (Bode et al., 2012). Mouse studies have also suggested that SFA and LPS act as potential activators of toll-like receptor 4 (TLR4) and its downstream regulatory gene NFKB1 (Shi et al., 2006). The gene $N F K B 1$ can stimulate the production of proinflammatory cytokines, including IL1 (Shirasuna et al., 2016). Despite the absence of clear molecular mechanisms, increased expression of the genes encoding proinflammatory cytokines and acute phase proteins in the visceral fat was also observed when energy allowance of nonpregnant dairy cows was increased (Ji et al., 2014). Taken together with the lower plasma NEFA concentration in the $\mathrm{HE}$ compared with CON group prepartum, we may speculate that the HE group had less SFA influx into the liver, leading to a lower grade of inflammation than in the CON group at 1 wk before parturition.

Although prepartal high-energy feeding reduced hepatic inflammatory response at $-8 \mathrm{~d}$, the difference in inflammatory status disappeared after parturition. Considering the changes over time, we observed that cows in both groups displayed maximal hepatic expression of various cytokine receptors and acute phase proteins at $1 \mathrm{~d}$, including interleukin 1 receptor type 2 (IL1R2), interleukin 4 receptor $(I L 4 R)$, interleukin 10 receptor subunit $\beta$ (IL10RB), SAA3, serum amyloid A4 (SAA4), HP, and $L B P$ (Figure 2). The results are in line with the observations by Loor et al. (2005) and Saremi et al. (2012, 2013), suggesting peaked cytokine signaling and acute phase response at parturition due to the systemic inflammation and tissue injury in the uterus. The increase of inflammation at parturition in both groups may have eliminated the difference in the inflammatory response between the 2 groups after parturition.

Previous findings suggested that high-energy intake during the dry period resulted in negative effects on the performance and metabolism of dairy cows after parturition (Dann et al., 2006). However, we observed no impairment in the hepatic metabolism after parturition based on the gene expression profiles, as no pathway was significantly affected by the high-energy feeding at 1 and $9 \mathrm{~d}$. The reason could be that the extent of the high-energy feeding in the present study was insufficient to induce a significant change in the adiposity of cows, as indicated by the similar BCS and systemic insulin sensitivity between the 2 groups around calving reported in our previous publications (Selim et al., 
2014; Salin et al., 2017). The adiposity of cows may act as an important factor that influences the liver function (Roche et al., 2015). Thus, the differences in hepatic metabolism between the groups in the present study may have been limited due to the similar adiposity.

\section{Hepatic Sphingolipid Profile and Its Association with Inflammation}

The metabolism of Cer is closely associated with inflammation and IR, according to findings in mice (Chavez and Summers, 2012). Recently, associations between plasma and hepatic Cer and HexCer levels and insulin sensitivity were observed in dairy cows after parturition (Rico et al., 2015, 2017). By comparing the Cer profiles between lean and overweight cows, Rico et al. (2017) found that after parturition plasma Cer (16:0) and Cer (24:0) levels were inversely associated with insulin sensitivity. In the present study, we observed negative correlations between BCS at 2 wk prepartum and the concentrations of various Cer subclasses at $-8 \mathrm{~d}$, suggesting that before parturition the potentially overweight cows may have lower hepatic Cer levels. Our observation corresponds to the finding of Rico et al. (2017), suggesting that overweight cows tended to have lower levels of Cer (16:0), Cer (24:0), and total Cer in the liver compared with lean cows before parturition.

The concentrations of various SM subclasses were higher in the HE group compared with the CON group. The SM hydrolysis is catalyzed by acid sphingomyelinase (ASMase). The enzyme ASMase was found to be activated in LPS-induced acute inflammation in mice (Wong et al., 2000), and its activation was IL1-dependent (Jenkins et al., 2010). Moreover, a stimulatory effect of SFA on the activity of ASMase was observed in human cells, as it amplified the activation of TLR 4induced inflammatory signaling (Jin et al., 2013; Lu et al., 2015). Collectively, the high-energy feeding of dry cows may have suppressed the hepatic inflammatory response through the downregulation of NFKB1 and IL1 expression by decreasing the hepatic SFA influx at $-8 \mathrm{~d}$, which subsequently reduced ASMase activity. As a consequence, the SM hydrolysis was decreased, resulting in higher hepatic SM concentrations in the HE group than in the CON group, as suggested by the negative correlation between IL1A expression and hepatic C20-SM concentration. In addition, the negative correlation between $S A A 3$ expression and C18-SM concentration and that between $L B P$ expression and the concentrations of C16- and C18-SM may further support the relationship between inflammation and SM hydrolysis.
It is worth noting that negative correlations were also observed between the relative expression level of acute phase proteins ( $S A A 3$ and $L B P$ ) and the concentrations of several Cer subclasses containing very long-chain or unsaturated fatty acids [MUFA-Cer, Cer (25:1), and Cer (24:1)], which appeared in higher concentrations in the HE group compared with the CON group similarly as SM. Although evidence exists that several inflammation-related genes are regulated by a mechanism that involves Cer subspecies (Maceyka and Spiegel, 2014), the role of Cer subspecies in the hepatic metabolism is uncertain. The concentrations of total Cer and most Cer subclasses [with Cer (24:1) and Cer (25:1) being the exceptions] were not different between the 2 groups at $-8 \mathrm{~d}$ in spite of the potentially lower SM hydrolysis in the HE compared with the CON group, suggested by the difference in SM concentrations (Qin et al., 2017). Thus, we suggest that the Cer production may have been supplied through other pathways, including the salvage pathway from other complex sphingolipids and the de novo synthesis from dietary nutrients (Merrill, 2011).

In addition to the differences between groups, we observed time-related differences in hepatic sphingolipid concentration regardless of the diet. The majority of Cer and SM subspecies that varied over time displayed lower concentrations at $9 \mathrm{~d}$ relative to -8 d (Supplemental Table S1; https://doi.org/10.3168/ jds.2017-13153). Rico et al. (2017) reported increases in hepatic Cer (24:0) and total Cer concentrations in dairy cows during the periparturient period. However, the increases in Cer concentrations were mainly obvious in the overweight cows but not in lean cows. Rico et al. (2017) grouped the cows based on their BCS, whereas in the present study prepartal high-energy feeding did not affect BCS before calving (Salin et al., 2017), suggesting less difference in the adiposity between groups compared with Rico et al. (2017), which might explain the difference between results.

The changes in sphingolipid concentrations over time were reflected in the expression of serine palmitoyltransferase small subunit A (SPTSSA) and serine palmitoyltransferase small subunit B (SPTSSB), which are 2 genes regulating the rate-limiting enzyme serine palmitoyltransferase (SPT) in Cer de novo synthesis (Han et al., 2009). Gene SPTSSB was expressed at lower levels at $9 \mathrm{~d}$ relative to $-8 \mathrm{~d}$ (Figure 2), corresponding to the patterns of most Cer subspecies over time, whereas the expression of SPTSSA increased after parturition, corresponding to the pattern of Cer (23:0) over time. The different expression patterns of the 2 SPT small subunits over time may suggest that these small subunits could have influenced the fatty 
acyl-CoA selectivity of SPT, as suggested by Han et al. (2009). Alternatively, the declines in most hepatic Cer over time may have resulted from the increased lipoprotein export of Cer when higher amount NEFA entered liver (Watt et al., 2012), as suggested by the negative correlation between plasma NEFA concentration and hepatic Cer concentrations postpartum. The increased hepatic export of Cer may occur to compensate plasma Cer level, as suggested by Rico et al. (2017), showing the elevation in plasma total Cer and Cer (24:0) concentrations after parturition. The exported Cer may contribute to the regulation of peripheral insulin sensitivity (Rico et al., 2015, 2017). The apparently contradictory negative correlation between hepatic Cer (24:0) and glucose area under curve in IVGTT after parturition may accentuate the role of hepatic lipoprotein export in the regulation of systemic insulin sensitivity.

\section{CONCLUSIONS}

The effects of prepartal high-energy intake on the hepatic adaptation of dairy cows were reflected in gene expression and sphingolipid profiles prepartum, whereas postpartal hepatic gene expression and sphingolipid profiles were not affected. In the absence of change in BCS, the observed prepartal effects were most likely due to the greater energy balance and decreased hepatic NEFA influx. Specifically, prepartal high-energy feeding increased hepatic lipogenesis before parturition by upregulating $L X R / R X R$ pathway and lipogenic gene THRSP at gene expression level. Moreover, prepartal high-energy feeding suppressed hepatic inflammatory and acute phase responses before parturition, as supported by the downregulated expression of proinflammatory genes IL1 and NFKB1 and acute phase protein-coding genes $S A A 3, H P$, and $L B P$. Subsequently, reduced inflammation in the liver may have contributed to the increased hepatic concentrations of C18-, C20-, C21-, C23-sphingomyelin, and total saturated sphingomyelin through the downregulation of sphingomyelin hydrolysis. Regardless of the diet, the cows displayed an increase in hepatic lipogenesis at gene expression level from $8 \mathrm{~d}$ prepartum to $9 \mathrm{~d}$ postpartum and decreases in the concentration of most ceramide and sphingomyelin subspecies detected in lipidomic analysis. Collectively, prepartal high-energy feeding did not disturb the hepatic adaptation of dairy cows during the periparturient period.

\section{ACKNOWLEDGMENTS}

This study was funded by the Ministry of Agriculture and Forestry (Helsinki, Finland), Suomen Naudan- jalostussäätiö Foundation (Hamina, Finland), and by the Future Fund (University of Helsinki). N. Qin was supported by the Doctoral Programme in Sustainable Use of Renewable Natural Resources (AGFOREE) of the University of Helsinki. The authors are grateful to Juha Suomi and his staff at the research farm of the University of Helsinki for their help in caring for the cows used in this study.

\section{REFERENCES}

Aiello, R. J., T. Kenna, and J. Herbein. 1984. Hepatic gluconeogenic and ketogenic interrelationships in the lactating cow. J. Dairy Sci. 67:1707-1715.

Akbar, H., E. Schmitt, M. A. Ballou, M. N. Correa, E. J. Depeters, and J. J. Loor. 2013. Dietary lipid during late-pregnancy and early-lactation to manipulate metabolic and inflammatory gene network expression in dairy cattle liver with a focus on PPARs. Gene Regul. Syst. Bio. 7:103-123.

Bell, A. W. 1995. Regulation of organic nutrient metabolism during transition from late pregnancy to early lactation. J. Anim. Sci. 73:2804-2819.

Bell, A. W., and D. E. Bauman. 1997. Adaptations of glucose metabolism during pregnancy and lactation. J. Mammary Gland Biol. Neoplasia 2:265-278.

Benjamini, Y., and Y. Hochberg. 2000. On the adaptive control of the false discovery fate in multiple testing with independent statistics. J. Educ. Behav. Stat. 25:60-83.

Bionaz, M., E. Trevisi, L. Calamari, F. Librandi, A. Ferrari, and G. Bertoni. 2007. Plasma paraoxonase, health, inflammatory conditions, and liver function in transition dairy cows. J. Dairy Sci. 90:1740-1750.

Bode, J. G., U. Albrecht, D. Haeussinger, P. C. Heinrich, and F. Schaper. 2012. Hepatic acute phase proteins-Regulation by IL6-and IL-1-type cytokines involving STAT3 and its crosstalk with NF-kappa B-dependent signaling. Eur. J. Cell Biol. 91:496-505.

Chavez, J. A., and S. A. Summers. 2012. A ceramide-centric view of insulin resistance. Cell Metab. 15:585-594.

Cui, Y., Z. Liu, X. Sun, X. Hou, B. Qu, F. Zhao, X. Gao, Z. Sun, and Q. Li. 2015. Thyroid hormone responsive protein spot 14 enhances lipogenesis in bovine mammary epithelial cells. In Vitro Cell. Dev. Biol. Anim. 51:586-594.

Dann, H. M., N. B. Litherland, J. P. Underwood, M. Bionaz, A. D'Angelo, J. W. McFadden, and J. K. Drackley. 2006. Diets during far-off and close-up dry periods affect periparturient metabolism and lactation in multiparous cows. J. Dairy Sci. 89:3563-3577.

De Koster, J., M. Hostens, M. Van Eetvelde, K. Hermans, S. Moerman, H. Bogaert, E. Depreester, W. Van den Broeck, and G. Opsomer. 2015. Insulin response of the glucose and fatty acid metabolism in dry dairy cows across a range of body condition scores. J. Dairy Sci. 98:4580-4592.

Douglas, G. N., T. R. Overton, H. G. Bateman, H. M. Dann, and J. K. Drackley. 2006. Prepartal plane of nutrition, regardless of dietary energy source, affects periparturient metabolism and dry matter intake in Holstein cows. J. Dairy Sci. 89:2141-2157.

Drackley, J., H. Dann, G. Douglas, N. Guretzky, N. Litherland, J. Underwood, and J. Loor. 2005. Physiological and pathological adaptations in dairy cows that may increase susceptibility to periparturient diseases and disorders. Ital. J. Anim. Sci. 4:323-344.

Drackley, J. K., T. R. Overton, and G. N. Douglas. 2001. Adaptations of glucose and long-chain fatty acid metabolism in liver of dairy cows during the periparturient period. J. Dairy Sci. 84:E100-E112.

Gross, J. J., F. J. Schwarz, K. Eder, H. A. van Dorland, and R. M. Bruckmaier. 2013. Liver fat content and lipid metabolism in dairy cows during early lactation and during a mid-lactation feed restriction. J. Dairy Sci. 96:5008-5017. 
Grummer, R. R., D. G. Mashek, and A. Hayirli. 2004. Dry matter intake and energy balance in the transition period. Vet. Clin. North Am. Food Anim. Pract. 20:447-470.

Han, G., S. D. Gupta, K. Gable, S. Niranjanakumari, P. Moitra, F. Eichler, R. H. Brown Jr., J. M. Harmon, and T. M. Dunn. 2009 Identification of small subunits of mammalian serine palmitoyltransferase that confer distinct acyl-CoA substrate specificities. Proc. Natl. Acad. Sci. USA 106:9931.

Herdt, T. H. 2000. Ruminant adaptation to negative energy balance - influences on the etiology of ketosis and fatty liver. Vet. Clin. North Am. Food Anim. Pract. 16:215-230.

Imhasly, S., C. Bieli, H. Naegeli, L. Nystroem, M. Ruetten, and C. Gerspach. 2015. Blood plasma lipidome profile of dairy cows during the transition period. BMC Vet. Res. 11:252.

Ingvartsen, K. L. 2006. Feeding- and management-related diseases in the transition cow-Physiological adaptations around calving and strategies to reduce feeding-related diseases. Anim. Feed Sci. Technol. 126:175-213.

Irizarry, R. A., B. Hobbs, F. Collin, Y. Beazer-Barclay, K. Antonellis, U. Scherf, and T. Speed. 2003. Exploration, normalization, and summaries of high density oligonucleotide array probe level data. Biostatistics 4:249-264.

Jain, N., J. Thatte, T. Braciale, K. Ley, M. O'Connell, and J. K. Lee. 2003. Local-pooled-error test for identifying differentially expressed genes with a small number of replicated microarrays. Bioinformatics 19:1945-1951.

Janovick, N. A., Y. R. Boisclair, and J. K. Drackley. 2011. Prepartum dietary energy intake affects metabolism and health during the periparturient period in primiparous and multiparous Holstein cows. J. Dairy Sci. 94:1385-1400.

Jenkins, R. W., D. Canals, J. Idkowiak-Baldys, F. Simbari, P. Roddy D. M. Perry, K. Kitatani, C. Luberto, and Y. A. Hannun. 2010. Regulated secretion of acid sphingomyelinase. Implications for selectivity of ceramide formation. J. Biol. Chem. 285:35706-35718.

Ji, P., J. K. Drackley, M. J. Khan, and J. J. Loor. 2014. Inflammationand lipid metabolism-related gene network expression in visceral and subcutaneous adipose depots of Holstein cows. J. Dairy Sci. 97:3441-3448.

Jiménez-Marín, Á., M. Collado-Romero, M. Ramirez-Boo, C. Arce, and J. J. Garrido. 2009. Biological pathway analysis by ArrayUnlock and ingenuity pathway analysis. BMC Proc. 3(suppl 4):S6.

Jin, J., X. Zhang, Z. Lu, D. M. Perry, Y. Li, S. B. Russo, L. A. Cowart, Y. A. Hannun, and Y. Huang. 2013. Acid sphingomyelinase plays a key role in palmitic acid-amplified inflammatory signaling triggered by lipopolysaccharide at low concentrations in macrophages. Am. J. Physiol. Endocrinol. Metab. 305:E853-E867.

Kallio, M. A., J. T. Tuimala, T. Hupponen, P. Klemela, M. Gentile, I. Scheinin, M. Koski, J. Kaki, and E. I. Korpelainen. 2011. Chipster: User-friendly analysis software for microarray and other highthroughput data. BMC Genomics 12:507.

Khan, M. J., C. B. Jacometo, D. E. Graugnard, M. N. Correa, E. Schmitt, F. Cardoso, and J. J. Loor. 2014. Overfeeding dairy cattle during late-pregnancy alters hepatic PPARalpha-regulated pathways including hepatokines: Impact on metabolism and peripheral insulin sensitivity. Gene Regul. Syst. Bio. 8:97-111.

Larsen, P. J., and N. Tennagels. 2014. On ceramides, other sphingolipids and impaired glucose homeostasis. Mol. Metab. 3:252-260.

Loor, J. J., H. M. Dann, R. E. Everts, R. Oliveira, C. A. Green, N. A. J. Guretzky, S. L. Rodriguez-Zas, H. A. Lewin, and J. K. Drackley. 2005. Temporal gene expression profiling of liver from periparturient dairy cows reveals complex adaptive mechanisms in hepatic function. Physiol. Genomics 23:217-226.

Loor, J. J., H. M. Dann, N. A. J. Guretzky, R. E. Everts, R. Oliveira, C. A. Green, N. B. Litherland, S. L. Rodriguez-Zas, H. A. Lewin, and J. K. Drackley. 2006. Plane of nutrition prepartum alters hepatic gene expression and function in dairy cows as assessed by longitudinal transcript and metabolic profiling. Physiol. Genomics 27:29-41.

Lu, Z., Y. Li, J. Jin, X. Zhang, Y. A. Hannun, and Y. Huang. 2015. GPR40/FFA1 and neutral sphingomyelinase are involved in palmi- tate-boosted inflammatory response of microvascular endothelial cells to LPS. Atherosclerosis 240:163-173.

Luke. 2018. Finnish feed tables and feeding recommendations. Accessed Jan. 27, 2018. https://portal.mtt.fi/portal/page/portal/ Rehutaulukot/feed_tables_english.

Maceyka, M., and S. Spiegel. 2014. Sphingolipid metabolites in inflammatory disease. Nature 510:58-67.

Mann, S., D. V. Nydam, A. Abuelo, F. A. Leal Yepes, T. R. Overton, and J. J. Wakshlag. 2016. Insulin signaling, inflammation, and lipolysis in subcutaneous adipose tissue of transition dairy cows either overfed energy during the prepartum period or fed a controlled-energy diet. J. Dairy Sci. 99:6737-6752.

McArdle, M. A., O. M. Finucane, R. M. Connaughton, A. M. McMorrow, and H. M. Roche. 2013. Mechanisms of obesity-induced inflammation and insulin resistance: Insights into the emerging role of nutritional strategies. Front. Endocrinol. (Lausanne) 4:52.

McCarthy, S. D., S. M. Waters, D. A. Kenny, M. G. Diskin, R. Fitzpatrick, J. Patton, D. C. Wathes, and D. G. Morris. 2010. Negative energy balance and hepatic gene expression patterns in highyielding dairy cows during the early postpartum period: A global approach. Physiol. Genomics 42A:188-199.

Merrill, A. H., Jr. 2011. Sphingolipid and glycosphingolipid metabolic pathways in the era of sphingolipidomics. Chem. Rev. 111:63876422 .

Nakagawa, H., O. Yamamoto, S. Oikawa, H. Higuchi, A. Watanabe, and N. Katoh. 1997. Detection of serum haptoglobin by enzymelinked immunosorbent assay in cows with fatty liver. Res. Vet. Sci. $62: 137-141$

Nygren, H., T. Seppanen-Laakso, S. Castillo, T. Hyotylainen, and M. Oresic. 2011. Liquid chromatography-mass spectrometry (LCMS)-based lipidomics for studies of body fluids and tissues. Methods Mol. Biol. 708:247-257.

Qin, N., T. Kokkonen, S. Salin, T. Seppanen-Laakso, J. Taponen, A. Vanhatalo, and K. Elo. 2017. Prepartal overfeeding alters the lipidomic profiles in the liver and the adipose tissue of transition dairy cows. Metabolomics 13:21.

Rico, J. E., V. V. R. Bandaru, J. M. Dorskind, N. J. Haughey, and J. W. McFadden. 2015. Plasma ceramides are elevated in overweight holstein dairy cows experiencing greater lipolysis and insulin resistance during the transition from late pregnancy to early lactation. J. Dairy Sci. 98:7757-7770.

Rico, J. E., S. S. Samii, A. T. Mathews, J. Lovett, N. J. Haughey, and J. W. McFadden. 2017. Temporal changes in sphingolipids and systemic insulin sensitivity during the transition from gestation to lactation. PLoS One 12:e0176787.

Roche, J. R., S. Meier, A. Heiser, M. D. Mitchell, C. G. Walker, M. A. Crookenden, M. V. Riboni, J. J. Loor, and J. K. Kay. 2015. Effects of precalving body condition score and prepartum feeding level on production, reproduction, and health parameters in pasture-based transition dairy cows. J. Dairy Sci. 98:7164-7182.

Salin, S., A. Vanhatalo, K. Elo, J. Taponen, R. C. Boston, and T. Kokkonen. 2017. Effects of dietary energy allowance and decline in dry matter intake during the dry period on responses to glucose and insulin in transition dairy cows. J. Dairy Sci. 100:5266-5280.

Saremi, B., A. Al-Dawood, S. Winand, U. Mueller, J. Pappritz, D. von Soosten, J. Rehage, S. Daenicke, S. Haeussler, M. Mielenz, and H. Sauerwein. 2012. Bovine haptoglobin as an adipokine: Serum concentrations and tissue expression in dairy cows receiving a conjugated linoleic acids supplement throughout lactation. Vet. Immunol. Immunopathol. 146:201-211.

Saremi, B., M. Mielenz, M. M. Rahman, A. Hosseini, C. Kopp, S. Daenicke, F. Ceciliani, and H. Sauerwein. 2013. Hepatic and extrahepatic expression of serum amyloid A3 during lactation in dairy cows. J. Dairy Sci. 96:6944-6954.

Schultz, J. R., H. Tu, A. Luk, J. Repa, J. Medina, L. Li, S. Schwendner, S. Wang, M. Thoolen, D. Mangelsdorf, K. Lustig, and B. Shan. 2000. Role of LXRs in control of lipogenesis. Genes Dev $14: 2831-2838$

Selim, S., T. Kokkonen, J. Taponen, A. Vanhatalo, and K. Elo. 2015. Effect of prepartal ad libitum feeding of grass silage on transcrip- 
tional adaptations of the liver and subcutaneous adipose tissue in dairy cows during the periparturient period. J. Dairy Sci. 98:55155528 .

Selim, S., S. Salin, J. Taponen, A. Vanhatalo, T. Kokkonen, and K. T. Elo. 2014. Prepartal dietary energy alters transcriptional adaptations of the liver and subcutaneous adipose tissue of dairy cows during the transition period. Physiol. Genomics 46:328-337.

Shahzad, K., M. Bionaz, E. Trevisi, G. Bertoni, S. L. Rodriguez-Zas, and J. J. Loor. 2014. Integrative analyses of hepatic differentially expressed genes and blood biomarkers during the peripartal period between dairy cows overfed or restricted-fed energy prepartum. PLoS One 9:e99757.

Shi, H., M. V. Kokoeva, K. Inouye, I. Tzameli, H. Yin, and J. S. Flier 2006. TLR4 links innate immunity and fatty acid-induced insulin resistance. J. Clin. Invest. 116:3015-3025.

Shirasuna, K., H. Takano, K. Seno, A. Ohtsu, T. Karasawa, M. Takahashi, A. Ohkuchi, H. Suzuki, S. Matsubara, H. Iwata, and T. Kuwayama. 2016. Palmitic acid induces interleukin-1 beta secretion via NLRP3 inflammasomes and inflammatory responses through ROS production in human placental cells. J. Reprod. Immunol. 116:104-112.

Trevisi, E., M. Amadori, S. Cogrossi, E. Razzuoli, and G. Bertoni. 2012. Metabolic stress and inflammatory response in high-yielding, periparturient dairy cows. Res. Vet. Sci. 93:695-704.

Vernon, R. G. 2005. Lipid metabolism during lactation: A review of adipose tissue-liver interactions and the development of fatty liver. J. Dairy Res. 72:460-469.
Watt, M. J., A. C. Barnett, C. R. Bruce, S. Schenk, J. F. Horowitz, and A. J. Hoy. 2012. Regulation of plasma ceramide levels with fatty acid oversupply: Evidence that the liver detects and secretes de novo synthesised ceramide. Diabetologia 55:2741-2746.

Wong, M. L., B. Xie, N. Beatini, P. Phu, S. Marathe, A. Johns, P. Golds, E. Hirsch, K. Williams, J. Licinio, and I. Tabas. 2000 Acute systemic inflammation up-regulates secretory sphingomyelinase in vivo: A possible link between inflammatory cytokines and atherogenesis. Proc. Natl. Acad. Sci. USA 97:8681-8686.

Wu, J., C. Wang, S. Li, S. Li, W. Wang, J. Li, Y. Chi, H. Yang, X. Kong, Y. Zhou, C. Dong, F. Wang, G. Xu, J. Yang, J. Gustafsson, and Y. Guan. 2013. Thyroid hormone-responsive SPOT 14 homolog promotes hepatic lipogenesis, and its expression is regulated by liver $\mathrm{X}$ receptor through a sterol regulatory element-binding protein 1c-dependent mechanism in mice. Hepatology 58:617-628.

Xia, J., I. V. Sinelnikov, B. Han, and D. S. Wishart. 2015. MetaboAnalyst 3.0-making metabolomics more meaningful. Nucleic Acids Res. 43:W251-7.

Yao, D. W., J. Luo, Q. Y. He, M. Wu, H. B. Shi, H. Wang, M. Wang, H. F. Xu, and J. J. Loor. 2016. Thyroid hormone responsive (THRSP) promotes the synthesis of medium-chain fatty acids in goat mammary epithelial cells. J. Dairy Sci. 99:3124-3133. 